\title{
Some Comments on the Present Consensus Arrangement and its Implications to World Trade
}

\author{
by Axel Wallen*
}

It will soon be years since the first agreement was made on restrictions of export credit subsidies in general, which has become the more elaborate Arrangement in force today.

A threat of growing protectionism in the form of official export subsidies has already been apparent, especially in the $60 \mathrm{~s}$, but has become much more evident since industrialized countries started to combat the first oil crisis in the mid-70s by increasing their own exports. Many years earlier the GATT rules had been worked out and adopted in order to bar import restrictions. In the 70s it became equally necessary to find ways to limit harmful official measures in the other side of trade - in the export field - to avoid disturbance of free market forces by officially financed subsidies.

In short, the Consensus Arrangement between OECD members on limiting official export subsidies means:

a minimum interest rate matrix below which members may not subsidize if their market rates are above the matrix,

a range of maximum credit periods and

an agreed minimum downpayment.

All recipient countries are, from export credit point of view, divided into three groups; one for countries with a GNP pc of more than 4,000 USD, one for the least developed countries with access to IDA loans and one for all countries in between. These groups are named Category I - III from the richest to the poorest ones, and both the matrix for minimum interest rates and the rules for the maximum credit periods are differentiated according to the country classification.

At the present the minimum interest rates in matrix vary between 12.2 per cent in Category I and 9.8 per cent in Category III while maximum credit periods vary between 10 and 5 years in the same categories. The minimum downpayment is 15 per cent.

For the last two years there has been a prohibition in the guidelines to deviate from the principal rules in the Consensus. Earlier it had been possible, after prior notification to all other Participants and a waiting period of 10 to 20 days.

\footnotetext{
* Exportkredit, Stockholm.
} 
When, however, a Participant provides what is called genuine aid in an export credit package, he is entitled to deviate from the Consensus guidelines. Genuine aid means that there is an official grant element in the transaction of at least 25 per cent according to a special international calculation (ODA). However he has to provide prior notification with a waiting period of 20 days if the grant element is less than 50 per cent.

It has been asked if this arrangement really takes into account future international trade.

The Consensus has always been and will probably remain a rather weak compromise, and will, it is to be hoped, develop in the direction of gradually reducing trade distortion by export credit subsidies of a different kind. As such, it was created by industrialized and fiercely competitive export countries in the belief that competition with the support of governmental or other official subsidies is in the long run self-destructive and should be abolished.

There is, however, no general adherence to this idea. Practically all Participants sometimes feel inclined to make efforts to win a competition for internal "national interest" reasons, using methods which they would not like others to use. Some, however, feel even more inclined to subsidies, and see reasons why they should not be abolished. Especially in times like the present, where international credit trade is declining as a consequence of the debt crisis, some participants argue that the granting of official subsidies from industrialized countries is a reasonable means to keep a flow of resources alive to a wide range of LDCs, which could not afford to buy at strictly commercial terms. On the whole, the work in the Consensus Group upholds the assumption that free trade and abstention from all kinds of subsidies are principles to be followed, irrespective of any fluctuations in the economic climate. If this is a wise arguement, it is more difficult to say. For economists in general this seems to be the case. For politicians, however, who are usually much more shortsighted, the principle of free trade may look attractive but unrealistic. Around us we see growing protectionism, as soon as trade balance figures begin deteriorating.

In summary one can say: The Consensus concept is in general based on the assumption that subsidies to export should be abolished as soon as possible, or at least reduced stepwise, and that this would be of benefit to world trade in the long run, whatever consequences in the short perspective such steps might create. On the other hand, one may say that the speed with which such steps are taken - the development of the Consensus Arrangement - is influenced by the trade climate which exists at any given moment, or by the different views on subsidies mentioned above.

After this short view on the purpose of the Consensus, a few comments on typical advantages and disadvantages of the Arrangement are in order.

At first it is easy to state that the necessity to build a relatively complicated system of rules has been a disadvantage: adherence to free trade and non-protectionistic principles would have led to a world where official export subsidies did not exist and where special guidelines were not needed. It is also easy to state that, in a world where these principles are not generally applied, it is an advantage to have a system of guidelines which gives at least a relative "protection against protectionism" in this field.

Looking a little closer at the Arrangement, there have been some insufficiencies which have created severe problems over several years. Thus the creation of a matrix with minimum interest rates between 7.5 and 9 per cent in 1976 led to a substantial increase in official subsidization, for two reasons. The first was that countries which had not so far initiated any financial 
export credit support found themselves immediately forced to do so, when they adopted the guidelines. Otherwise they would have been in a position clearly inferior to many competitors. This became much more evident as soon as general rules were adopted so one could see exactly how much subsidization one was entitled to give. And for most countries the matrix meant an increasing amount of such support, because most market rates went up drastically at the end of the $70 \mathrm{~s}$, while the matrix unfortunately remained practically unchanged for 5 years. This rigidity of the matrix was the second reason for the increase in subsidies following the adoption of the guidelines up to a maximum of about 5.5 billion USD in 1979-80.

It may be asked why was there such a reluctance to change the matrix - to raise it - when market rates went up substantially and in view of the general aim of the Consensus to reduce subsidies. In fact sometimes the matrix was 5-10 per cent below market rates of USD, GBP and FRF. The reason for the rigidity was a significant hesitation in some countries within the EC regarding the consequences of an effective common reduction of export credit subsidies. France and Italy in particular viewed with great doubt the possibilities for German and Japanese exporters to use their market rates, which were usually below the matrix without any official subsidization, and did not wish to see the gap widened between these market rates and the matrix level with official support, although the substantial exchange risk on the low market rates might have given economic balance.

In 1978-79 the Arrangement encountered a crisis because at deadlock between the EC, USA and Japan. In a study on the interest rate aspects, two different possibilities were laid out in order to reduce the damaging effect of the existing subsidies. One idea was the so-called $\mathrm{UMM}$ - a uniform moving matrix - which would keep a reasonable degree of subsidization but restrict it to Participants with their own market rates above an average of the rate of the major currencies. The matrix would swing according to the changes of this level every year or half year, thus reducing subsidies to a minor part of what they had been previously. The other idea was to impose a kind of controlled total ban of interest rate subsidization, by a system of differentiated rates where market rates were defined regularly for each currency involved and no subsidies allowed below these rates.

The problems and negative effects of the rigidity to change the matrix came to an end in the years 1982-83. Participants in general felt the level of subsidies too high and asked for an alignment, in view of the high market rates. The matrix was increased substantially by a couple of percentages up to 10-12 per cent and about the same time market rates began to drop. When they threatened to come down in general - specially the USD - through the matrix levels, all Participants found the UMM a working model and adopted it. And that is what we have today: a matrix swinging half-yearly according to the changes in an SDR-weighted average of the 5 most important currencies. In fact this means that the USD, as the most significant currency, directs the level of the matrix and it is in reality only the countries in Category III (and they are nowadays few and comparatively small importers) which benefit from rates below the USD rate according to the matrix.

All this has led to a substantial decrease in official export subsidies from perhaps 5 billion USD a year to less than $1 / 2$ billion USD nowadays. Of course this is an advantage over the previous situation - in view of our general aim to reduce subsidies. But there are two substantial disadvantages.

The first is the complicated, troublesome and impracticable system of controlled market rates which has been necessary with the development of the matrix on those currency interest rates 
which are below the present comparatively high matrix. We need them because in some countries official financial support is given to exporters by using low market rates from other countries and when such support is given (in the form of firm commitments at a tender) it is regarded necessary to balance the competition distorting effect by using standard interest rates. These so called CIRRs have, according to the Financial Times, been "the flop of the year". They are difficult to define, difficult to identify and thus difficult to follow. The group is presently working intensively on this problem.

Another negative consequence of the new system is apparent in the pattern of competition between political aims to strengthen at least on short sight the own country's export. When subsidies are reduced in interest rate support one could believe that the surplus in state budgets would be used for hospitals or schools but there are signs that subsidies to export which are saved through the Consensus take another disguise - by marrying aid efforts or going into highly risky export credit insurance - two ways of subsidies which are even more difficult to identify and thus more difficult to attack than earlier interest rate support.

Since the creation of UMM, a couple of years ago, the Consensus Group with OECD members has been mainly occupied in devising adequate measures to limit export credit subsidization which appears through mixing aid and trade. Here, it is very difficult to maintain the correct balance; on one side there are the disadvantages of distorting trade by using a reasonably small portion of aid grant, thus appropriating export transactions which would otherwise have gone to competitors, and on the other side, the disadvantages for some developing countries of not getting the same access to soft terms by mixing aid and trade for credit as earlier.

In this connection one should admit that the whole UMM system is, from the LDCs point of view, a disadvantage in comparison with the previous system - the possibilities for attaining soft terms within the Consensus system have disappeared just at a time when they, at least immediately, would have appeared most attractive and perhaps needed because of the heavy debt burden in LDCs. This effect of the new matrix system has probably contributed to the decrease in new projects in the developing world which we see now.

Rather naturally, some Participants argue that the distortive effect of using aid in the export credit field can only be eliminated by increasing substantially the lowest permissible grant element which allows a deviation from Consensus rules. They claim that a grant element not lower than 50 per cent would lead to the use of aid means only for real aid purposes, and only thus will it be possible to draw the line between aid and commercial transaction. At the same time it is clear that such a drastic increase would be a heavy blow to some of those LDCs which are a little better off and which have so far enjoyed benefit either from the earlier Consensus matrix or from mixed credits with a grant element around 25 per cent.

The foregoing has been an attempt to show the controversy surrounding the Consensus Arrangement. Unfortunately, it is not possible to create a system which is good for everyone. Above all one must accept that sovereign governments seldom want to bind themselves too tightly by international agreements, when they see that the room for political manouvering is threatened. With this in mind one might perhaps admit that the Consensus has, stepwise, arrived at a stage where the pros outweight the cons.

As noted, there have been signs that subsidies in increasing degree take the form of high risk insurance of political risk. This is of course a question to be looked into at the Berne 
Union, but since the IMF initiated a study on present attitudes by public insurance institutes we have also got discussions on these matters in the OECD.

Finally the major achievements of the scheme since its introduction may be summarized as follows:

- the moving matrix which reduces subsidies in relation to major currencies' market rates,

- the no-derogation agreement which generally forbids deviations from the guidelines,

- the new transparency rules tied aid credits - prior notification up to 50 per cent grant element, and

- a system for face to face consultations providing hopefully common lines and perhaps a growing discipline in this problematic field. 